\title{
Phenylethynyl-BODIPY Oligomers: Bright Dyes and Fluorescent Building Blocks
}

2009

Vol. 11, No. 1

85-88

\section{Yusuf Cakmak ${ }^{\dagger}$ and Engin U. Akkaya,}

Department of Chemistry, Middle East Technical University, 06531 Ankara, Turkey, and Department of Chemistry and UNAM-Institute of Materials Science and Nanotechnology, Bilkent University, 06800 Ankara, Turkey

eua@fen.bilkent.edu.tr

Received October 23, 2008

\section{ABSTRACT}

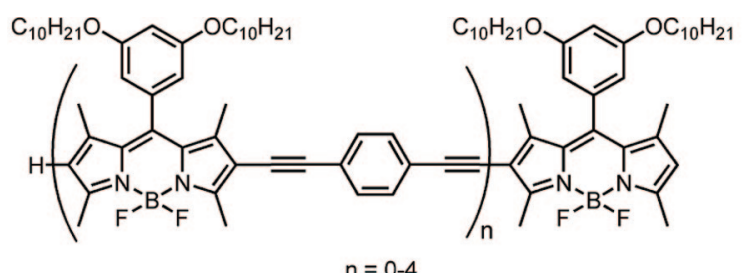

$n=0-4$

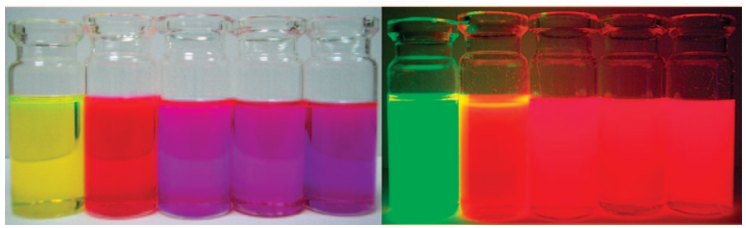

Boradiazaindacene dyes were converted into phenylethynyl-BODIPY oligomers via a cycle of reactions, notably including Sonogashira couplings. As expected, as the number, $n$, of repeating units increases, peak absorption and emission wavelengths are shifted to the red end of the visible spectrum, albeit with smaller increments as $n$ increases. Decyl groups help to keep the solubility remarkably high, and in addition to being very bright red-emitting fluorophores, their rigid rod-like structures could allow their use as functional building blocks.

As evidenced by the number of recent reviews, ${ }^{1}$ there has been increased interest in the derivatization of BODIPY dyes ${ }^{2}$ and their applications ${ }^{3}$ in recent years. Part of this interest is focused on finding novel strategies ${ }^{2 a, b, e, 4,5}$ to push the absorption and emission wavelengths further into the red. The parent dye is a green-emitting fluorophore, comparable to fluorescein; however, with structural modifications, the chromophore can be transformed into a red- to near-IRemitting dye.

${ }^{\dagger}$ Middle East Technical University.

Bilkent University.

(1) Recent reviews on BODIPY dyes:(a) Ulrich, G.; Ziessel, R.; Harriman, A. Angew. Chem., Int. Ed. 2008, 47, 1184-1201. (b) Ziessel, R.; Ulrich, G.; Harriman, A. New J. Chem. 2007, 31, 496-501. (c) Loudet, A.; Burgess, K. Chem. Rev. 2007, 107, 4891-4932.
In this report, we disclose our attempts to shift the dye's working range of wavelengths into red, by extending the conjugation on the 2,6-axis through iterative Sonogashira couplings, yielding the first examples of oligomeric BODIPY dyes. The synthesis plan is shown in Scheme 1. From the very start, we realized that as the BODIPY chain is extended, solubility is likely to become an issue.

(2) Selected examples:(a) Rurack, K.; Kollmannsberger, M.; Daub, J. Angew. Chem., Int. Ed. 2001, 40, 385-387. (b) Dost, Z.; Atilgan, S.; Akkaya, E. U. Tetrahedron 2006, 62, 8484-8888. (c) Ulrich, G.; Goze, C.; Guardigli, M.; Roda, A.; Ziessel, R. Angew. Chem., Int. Ed. 2005, 44, 3694-3698. (d) Baruah, M.; Qin, W.; Vallee, R. A. L.; Beljonne, D.; Rohand, T.; Dehaen, W.; Boens, N. Org. Lett. 2005, 7, 4377-4380. (e) Umezawa, K.; Nakamura, Y.; Makino, H.; Citterio, D.; Suzuki, K. J. Am. Chem. Soc. 2008, 130, 15501551. (f) Saki, N.; Dinc, T.; Akkaya, E. U. Tetrahedron 2006, 62, 27212725. (g) Thivierge, C.; Bandichhor, R.; Burgess, K. Org. Lett. 2007, 9 , 2135-2138. 
Scheme 1. Synthesis of Oligomeric Phenylethynyl-BODIPY Dyes: Dye $\mathbf{2}$ and Intermediates

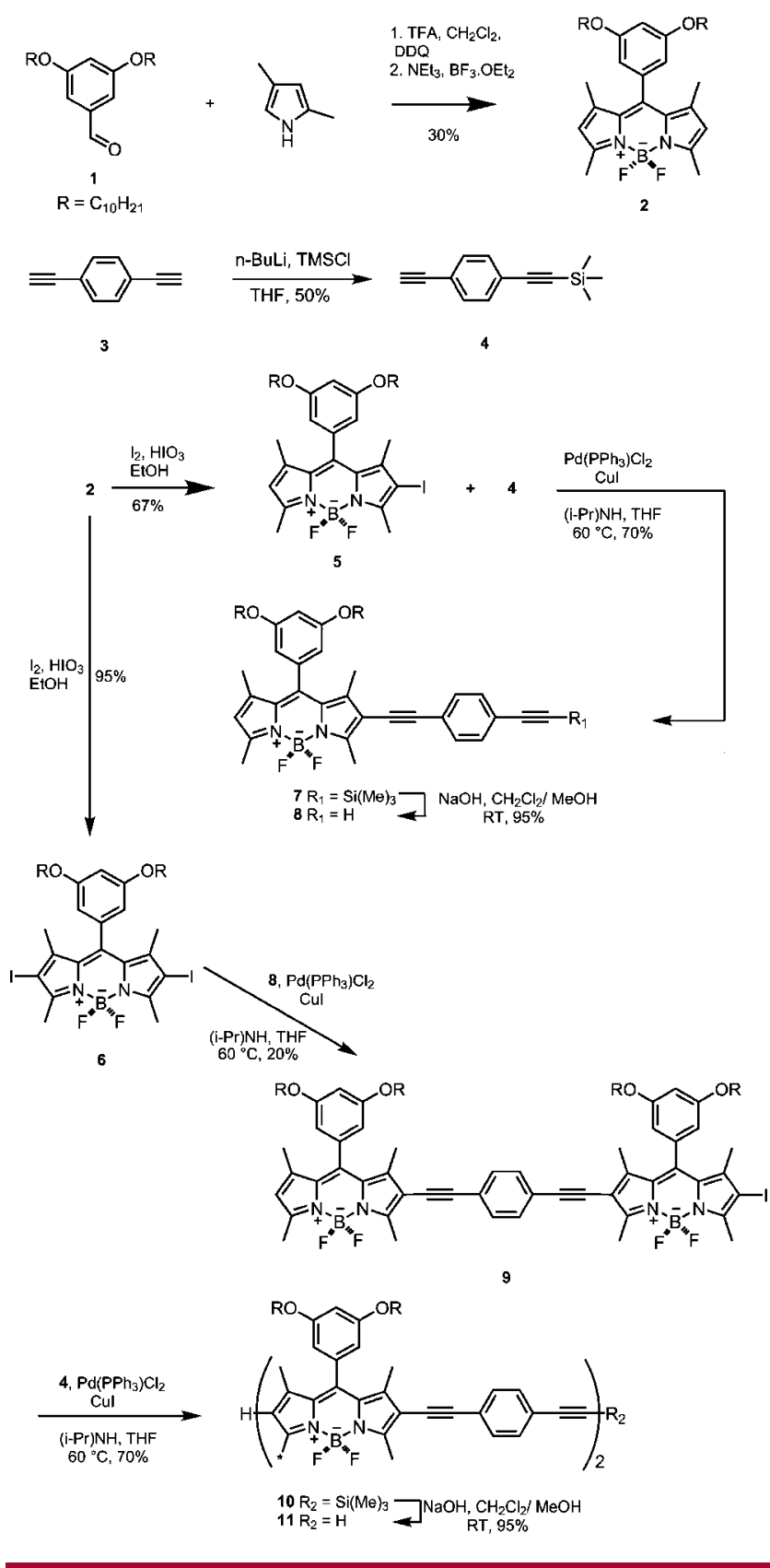

We placed two decyloxy functions on the meso-phenyl group of the BODIPY dyes. Thus, our synthetic work starts with the preparation of 3,5-didecyloxybenzaldehyde in

(3) (a) Atilgan, S.; Ekmekci, Z.; Dogan, A. L.; Guc, D.; Akkaya, E. U. Chem. Commun. 2006, 4398-4400. (b) Ertan-Ela, S.; Yilmaz, M. D.; Icli, B.; Dede, Y.; Icli, S.; Akkaya, E. U. Org. Lett. 2008, 10, 3299-3302. (c) Coskun, A.; Akkaya, E. U. J. Am. Chem. Soc. 2005, 127, 10464-10465. (d) Coskun, A.; Akkaya, E. U. J. Am. Chem. Soc. 2006, 128, 14474-14475. (e) Rurack, K.; Kollmannsberger, M.; Resch-Genger, U.; Daub, J. J. Am. Chem. Soc. 2000, 122, 968-969. (f) Zeng, L.; Miller, E. W.; Pralle, A.; Isacoff, E. Y.; Chang, C. J. J. Am. Chem. Soc. 2006, 128, 10-11. (g) Camerel, F.; Bonardi, L.; Ulrich, G.; Charbonniere, L.; Donnio, B.; Bourgogne, C.; Guillon, D.; Retailleau, P.; Ziessel, R. Chem. Mater. 2006 18, 5009-5021. (h) Coskun, A.; Yilmaz, M. D.; Akkaya, E. U. Org. Lett. 2007, 9, 607-609. (i) Park, M. S.; Swamy, K. M. K.; Lee, Y. J.; Lee, H. N.; Jang, Y. J.; Moon, Y. H.; Yoon, J. Tetrahedron Lett. 2006, 47, 8129-8132. analogy to the literature. ${ }^{6}$ Then, the BODIPY dye 2 was obtained following a rather routine procedure for the synthesis of this class of dyes. 1,4-Diethynylbenzene 3 and the mono-TMS-protected form of it (4) are important intermediates. The BODIPY dye 2 can be iodinated at the electron-rich positions 2 and 6 using an $\mathrm{I}_{2} / \mathrm{HIO}_{3}$ iodination procedure, ${ }^{7}$ and both monoiodinated (5) and diiodinated (6) products can be obtained in satisfactory yields by adjusting the dye to iodination reagent ratio (or the reaction time). 2-Iodo-BODIPY dye $\mathbf{5}$ was then subjected to Sonogashira coupling conditions $\left(\mathrm{Pd}\left(\mathrm{Ph}_{3}\right) \mathrm{Cl}_{2}\right.$ and $\mathrm{CuI}$ catalysis) and coupled to mono-TMS-protected 1,4-diethynylbenzene (4). The removal of the TMS protection yielded another useful intermediate, 8. 2,6-Diiodo derivative (6) when subjected to coupling with this intermediate results in the dimeric BODIPY derivative 9 where one iodo substituent is still present. Tweaking with the reaction conditions, result in the double coupling product which is the compound 13. The chain was further extended by reacting the intermediate compound 9 with mono-TMS-protected 1,4-diethynylbenzene, followed by deprotection, to yield another intermediate species 11. At this point, we had the parent dye $2(n=0)$ and the triBODIPY $13(n=2)$ already at hand. The other members of the oligomeric BODIPY series were obtained as follows, all through Sonogashira couplings: 1,4- diethynylbenzene with monoiodoBODIPY 5 yielded the diBODIPY 12 ( $n=1)$, and with the intermediate 9, the tetraBODIPY $14(n=3)$. Finally, the last member of the

Scheme 2. Synthesis of Oligomeric Phenylethynyl-BODIPY Dyes 12, 13, 14, and $\mathbf{1 5}$

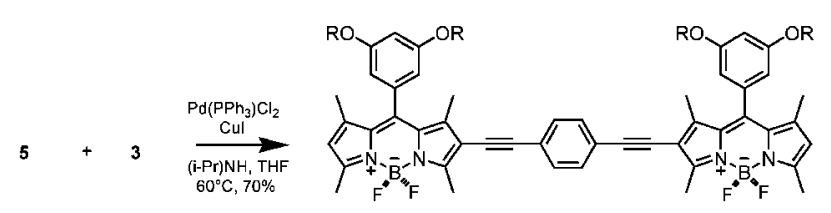

12

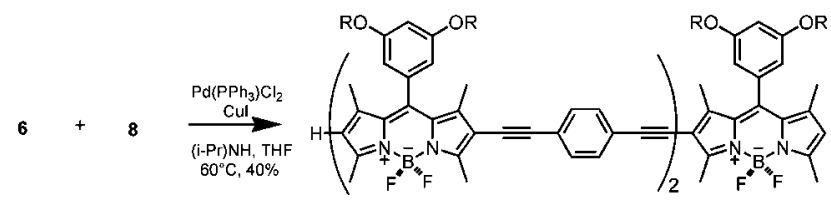

13

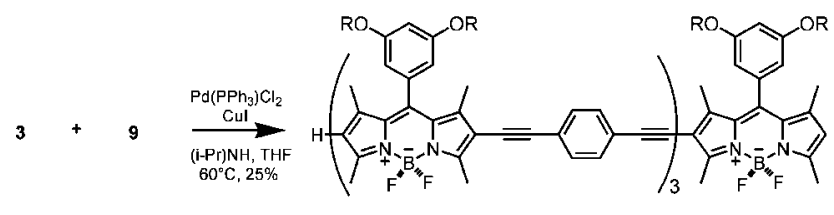

14

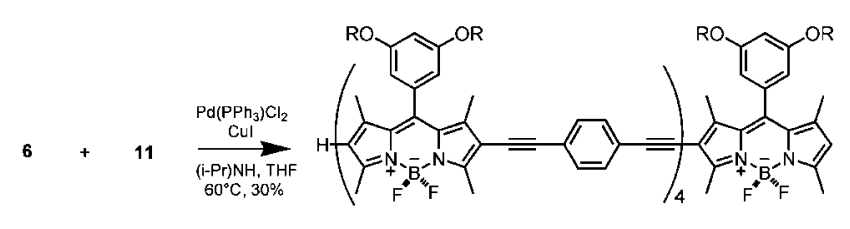

15 


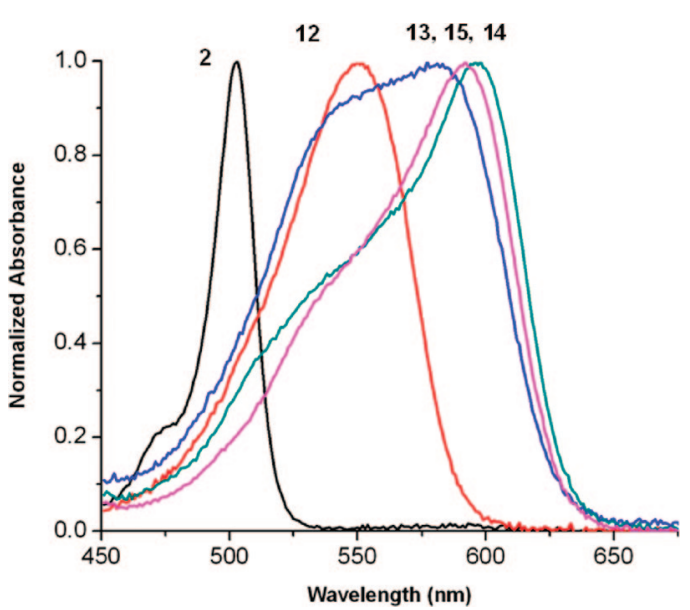

Figure 1. Normalized absorption spectra of the parent BODIPY and the oligomeric series in dilute $\mathrm{CHCl}_{3}$ solutions (black, 2; red, 12; blue, 13; green, 14; pink, 15).

series was obtained by the reaction of 2,6-diiodoBODIPY 6 with the intermediate $\mathbf{1 1}$ (Scheme 2).

Absorption spectra of the dyes in chloroform solutions were in accord with our expectations with a notable exception of compound 13. As $n$ was varied from 0 to 4 , there was a red shift of $120 \mathrm{~nm}$. However, with each addition of the repeating units, the additional red shifts becomes smaller: 0 to $1,+48 \mathrm{~nm} ; 1$ to $2,+28 \mathrm{~nm} ; 2$ to $3,+18 \mathrm{~nm}$. The peak position is practically unchanged for the dyes corresponding to $n=3$ (14) and $n=4(\mathbf{1 5})$. The absorbance peak due to compound $\mathbf{1 3}$ has a very peculiar shape and highly broadened. The peak is clearly the sum of two distinct peaks, which are most likely the results of Davydov (exciton) splitting of the excited states. As judged by the magnitude of fwhm values (Table 1), similar excitonic interactions might

Table 1. Spectroscopic Properties of the Parent BODIPY and Oligomeric Series

\begin{tabular}{lcccrc}
\hline dye & $\begin{array}{c}\lambda_{\max }(\mathrm{abs})^{a} \\
(\mathrm{~nm})\end{array}$ & \multicolumn{1}{c}{$\varepsilon_{\max }{ }^{a}$} & $\begin{array}{c}\lambda_{\max }(\mathrm{em})^{a} \\
(\mathrm{~nm})\end{array}$ & $\begin{array}{r}\mathrm{fwhm}^{a} \\
\left(\mathrm{~cm}^{-1}\right)\end{array}$ & $\Phi^{a}$ \\
\hline $\mathbf{2}$ & 503 & 95000 & 512 & 836 & $0.69^{b}$ \\
$\mathbf{1 2}$ & 551 & 69000 & 586 & 1235 & $0.39^{c}$ \\
$\mathbf{1 3}$ & 579 & 104000 & 621 & 1107 & $0.45^{d}$ \\
$\mathbf{1 4}$ & 597 & 118000 & 624 & 950 & $0.60^{d}$ \\
$\mathbf{1 5}$ & 592 & 251000 & 620 & 1011 & $0.58^{d}$
\end{tabular}

${ }^{a} \mathrm{In}_{\mathrm{CHCl}} \cdot{ }^{b}$ Fluorescein was used as the reference dye $(\Phi=0.92$ in $\left.0.1 \mathrm{M} \mathrm{NaOH}_{(\mathrm{ag})}\right) .{ }^{8}{ }^{c}$ Rhodamine $6 \mathrm{G}$ was used as the reference dye $(\Phi=$ 0.95 in EtOH $)^{9}{ }^{d}$ Sulforhodamine 101 was used as the reference dye $(\Phi=$ 0.9 in $\mathrm{EtOH}) .{ }^{10}$

be in effect in the other members of the series $(\mathbf{1 2}, \mathbf{1 4}$, and 15), but only in $\mathbf{1 3}$ do the two peaks have approximately equal heights. This phenomenon, which is a manifestion of dipole coupling of the chromophores, is quite common in multichromophoric systems ${ }^{11}$ and is not limited to crystalline or aggregate states, as many examples in dilute solutions have been reported. ${ }^{12}$ Further work on this matter is warranted for a better understanding of excitonic interactions in this series. Normalized emission spectra (Figure 2) show

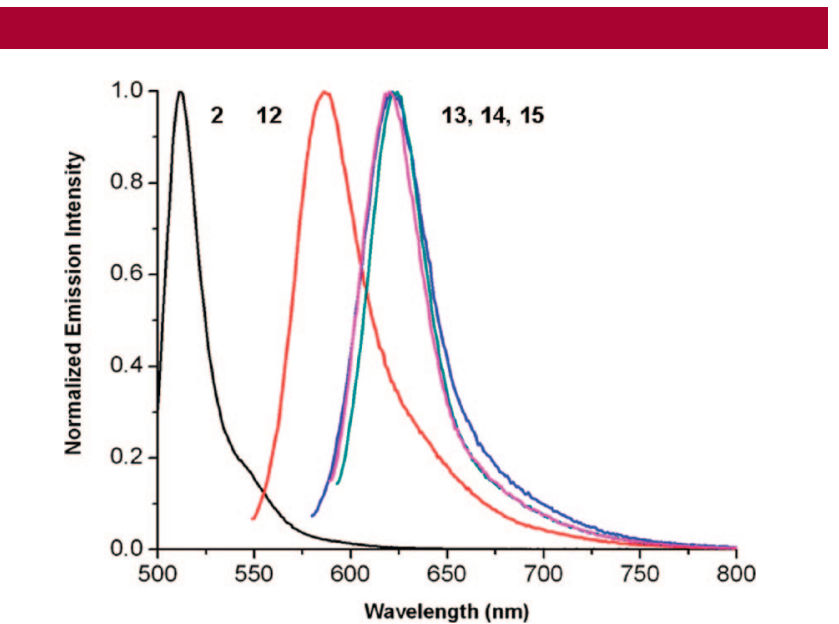

Figure 2. Normalized emission spectra of the parent BODIPY and the oligomeric series in dilute $\mathrm{CHCl}_{3}$ solutions (black, 2; red, 12; blue, 13; green, 14; pink, 15).

an expected trend, $n=0$ emits at $520 \mathrm{~nm}$, and the final member of the series emits at $640 \mathrm{~nm}$. Quantum yields and extinction coefficients were also determined (Table 1). As a result of the rigidity of the phenylethynyl framework in these compounds, quantum yields remain high even at longer wavelength emission compounds.

It is also worth mentioning that the Stokes shifts of the new fluorophores vary in the range of 27 to $42 \mathrm{~nm}$, which is significantly larger than that of a standard BODIPY dye, which is typically less than $10 \mathrm{~nm}$.

We expect these dyes to become valuable additions to the growing arsenal of red-emitting dyes, especially useful in biological applications. In addition, the rigid 3D structure of the phenylethynyl chromophores confer additional value to these dyes as potential building blocks in the construction of functional supramolecular assemblies. In fact, very recently, a polymeric material incorporating BODIPY units

(4) (a) Wada, M.; Ito, S.; Uno, H.; Murashima, T.; Ono, N.; Urano, T.; Urano, Y. Tetrahedron Lett. 2001, 42, 6711-6713. (b) Killoran, J.; O'Shea, D. F. Chem. Commun. 2006, 1503-1505. (c) Zhao, W.; Carreira, E. M. Chem. Eur. J. 2006, 12, 7254-7263.

(5) Zhang, D.; Wen, Y.; Xiao, Y.; Yu, G.; Liu, Y.; Qian, X. Chem. Commun. 2008, 4777-4779.

(6) Burghart, A.; Kim, H.; Welch, M. B.; Thorensen, L. H.; Reibenspies, J.; Burgess, K. J. Org. Chem. 1999, 64, 7813-7819.

(7) Yogo, T.; Urano, Y.; Ishitsuka, Y.; Maniwa, F.; Nagano, T. J. Am. Chem. Soc. 2005, 127, 12162-12163.

(8) Weber, G.; Teale, F. W. J. Trans. Faraday Soc. 1958, 54, 640-648.

(9) Kubin, R. F.; Fletcher, A. N. J. Lumin. 1982, 27, 455-462.

(10) Birge, R. R. Kodak Laser Dyes; Eastman Kodak Company: Rochester, NY, 1987.

(11) Scholes, G. D.; Ghiggino, K. P.; Oliver, A. M.; Paddon-Row, M. N. J. Am. Chem. Soc. 1993, 115, 4345-4349.

(12) (a) Hernando, J.; Schaaf, M. V. D.; van Dijk, E. M. H. P.; Sauer, M.; Garcia-Parajo, M. F.; van Hulst, N. F. J. Phys. Chem. A 2003, 107, 43-52. (b) Furstenberg, A.; Vauthey, E. J. Phys. Chem. B 2007, 111, 1261012620. (c) Mazzoni, M.; Agati, G.; Troup, G. J.; Pratesi, R. J. Opt. A: Pure Appl. Opt. 2003, 5, S374-S380. 
was reported ${ }^{13}$ to show interesting self-assembly properties. All of the dyes we reported have two open positions for further functionalization through electrophilic aromatic substitution of pyrrole moieties of the terminal BODIPYs. Further work with these rigid oligomers is expected to yield interesting applications in electrochromic devices and functional self-assembled systems.

(13) Nagai, A.; Miyake, J.; Kokado, K.; Nagata, Y.; Chujo, Y. J. Am Chem. Soc. 2008, 130, 15276-15278.
Acknowledgment. The authors gratefully acknowledge support from Turkish Academy of Sciences (TUBA).

Supporting Information Available: Synthesis procedures, additional spectroscopic data. This material is available free of charge via the Internet at http://pubs.acs.org.

OL802446E 